\title{
Correction to: Highly Sensitive Plus Shaped Cavity in Silicon Fiber for RI Detection of Water Samples
}

\author{
Lokendra Singh $^{1} \cdot$ Niteshkumar Agrawal $^{2} \cdot$ Chinmoy Saha ${ }^{3} \cdot$ Brij Mohan Singh ${ }^{1} \cdot$ Taresh Singh $^{1}$
}

Published online: 23 February 2022

(c) Springer Nature B.V. 2022

\section{Correction to: Silicon}

https://doi.org/10.1007/s12633-021-01519-0

The original version of the article unfortunately contained an error.

A data was inadvertently added in the second author's name Niteshkumar Agrawal. The correct author name is shown above.

The original article has been corrected.

Publisher's Note Springer Nature remains neutral with regard to jurisdictional claims in published maps and institutional affiliations.

The original article can be found online at https://doi.org/10.1007/ s12633-021-01519-0.

Lokendra Singh

kashyap00000@gmail.com

Niteshkumar Agrawal

nitagr26@gmail.com

1 School of Computing, University of Engineering and Technology Roorkee, Haridwar 247667, Uttarakhand, India

2 Pillai College of Engineering, New Panvel, Navi Mumbai 410206, Maharashtra, India

3 Department of Avionics, Indian Institute of Space Science and Technology, 695547 Thiruvananthapuram, Kerala, India 